doi https://doi.org/10.31977/grirfi.v22il.2765

Recebido: 17/12/2021 | Aprovado: 19/02/2022

Received: 12/17/2021 | Approved: 02/19/2022

\title{
TEMPORALIDADE EM HUSSERL
}

\author{
Everaldo Cescon ${ }^{1}$ \\ Universidade de Caxias do Sul (UCS) \\ http://orcid.org/0000-0002-0401-7294 \\ E-mail: ecescon@ucs.br
}

\section{RESUMO:}

O objetivo deste artigo é apresentar, na perspectiva de Edmund Husserl, os conceitos de consciência, de subjetividade e de tempo. Para o desenvolvimento desse intento são utilizados, principalmente, os seguintes textos originais husserlianos: Investigações Lógicas, Lições para uma Fenomenologia da Consciência Interna do Tempo e Meditações Cartesianas. Neste texto, é apresentado, inicialmente, o conceito de consciência como unidade real-fenomenológica das vivências do eu, como autoconsciência e como vivência intencional. A subjetividade é abordada a partir dos conceitos de eu empírico e de eu puro. Já o tempo é exposto sob o viés fenomenológico. Por fim, no último item, é abordada a relação intrínseca estabelecida entre os conceitos de tempo e de subjetividade, sendo evidenciado, assim, o conceito de fluxo absoluto de vivências, que é ausente de tempo, que é o absoluto último e verdadeiro. Paradoxalmente, é demonstrado que é no próprio fluxo que a temporalidade se origina, sendo na temporalidade, por intermédio das vivências, que a vida subjetiva se efetiva e se consolida. Ou seja, é explicitado que o tempo é o catalisador do desenvolvimento da subjetividade por intermédio das vivências temporais e que é nessa relação autogênica essencial que são criadas as condições para o desenrolar da vida em unidade, cujo processo é caracterizado pela abertura ao tempo, um fluir na perpetuidade viva do presente.

PALAVRAS-CHAVE: Husserl; Consciência; Subjetividade.

\section{TEMPORALITY IN HUSSERL}

\begin{abstract}
:
This paper aims to present, from the perspective of Edmund Husserl, the concepts of consciousness, subjectivity and time. For the development of such purpose, the following husserlian original texts have been mainly utilized: Logical Investigations, On the Phenomenology of the Consciousness of Internal Time and Cartesian Meditations. This text initially presents the concept of consciousness as a real phenomenological unity of the ego's experiences, as selfconsciousness and as intentional experiences will be exposed. Subjectivity is approached based on the concepts of empirical self and pure self. Time, on the other hand, is explored from a phenomenological standpoint. Finally, the last item shows the intrinsic relationship established between the concepts of time and subjectivity, thus demonstrating the concept of the absolute flow of experiencing, which is timeless, and which is the ultimate and true absolute. Paradoxically, it demonstrates that it is in the actual flow that temporality is originated, and it is in the temporality, through experiences, that subjective life is put into effect and is consolidated; i.e.,,it clearly demonstrates that time is the catalyst for the development of subjectivity through temporal experiences and that it is in the essential autogenic relationship that conditions are created for the development of life in unity, whose process is characterized by openness to time, a flow in the live perpetuity of the now.
\end{abstract}

KEYWORDS: Husserl; Consciousness; Subjectivity.

\footnotetext{
${ }^{1}$ Doutor(a) em Teologia pela Pontifícia Universidade Gregoriana (P.U.G), Itália.. Professor(a) da Universidade de Caxias do Sul (UCS), Caxias do Sul - RS, Brasil..
}

CESCON, Everaldo. Temporalidade em Husserl. Griot : Revista de Filosofia, Amargosa - BA, v.22 n.1, p.279-289, fevereiro, 2022. 


\section{Introdução}

Neste texto serão analisados alguns dos principais conceitos trazidos à luz pelo filósofo Edmund Husserl, quais sejam: a consciência, a subjetividade e o tempo. Sem dúvida, são conceitos repetidamente discutidos por inúmeros filósofos no período anterior, contemporâneo e posterior a Husserl; no entanto, esses conceitos são explicitados por esse pensador com peculiar originalidade e complexidade.

Constata-se pelas inúmeras interpretações expostas na bibliografia que expõe esses conceitos conforme o entendimento husserliano que esse tema é de difícil enfrentamento, especialmente devido às inúmeras divergências, as quais chegam, muitas vezes, a ser contraditórias. Assim, este texto propõe-se a explorar esses três conceitos de forma simples e didática, com suporte na bibliografia de Husserl e em alguns de seus comentadores, com o intuito de investigar, valendo-se do método hermenêutico, como a subjetividade e a consciência se constituem a partir da temporalidade.

O texto será desenvolvido em três partes. A primeira versará sobre a consciência, a subjetividade e o tempo. Conforme apreciado pelo pai da fenomenologia, a consciência será apresentada em três diferentes conceitos: 1) Como unidade real-fenomenológica das vivências do eu; 2) Como autoconsciência; 3) Como vivência intencional. Quanto à subjetividade, será efetuada uma abordagem a partir dos conceitos de "eu empírico" e de "eu puro". Esses conceitos, que são essenciais no entendimento da teoria fenomenológica, principalmente o conceito de consciência que perpassa a todo instante pelos outros dois, subsidiarão a feitura da terceira parte, que, por fim, abordará a relação intrínseca entre os conceitos de tempo e de subjetividade.

Conforme será explicitado nesta pesquisa, em uma filosofia rigorosa, é necessária a descrição da autogênese do absoluto último e verdadeiro. Essa descrição do absoluto só é possível pela investigação da relação constitutiva entre a subjetividade absoluta e o tempo, que implica a compreensão do fluxo constitutivo do tempo como subjetividade absoluta.

\section{Tempo}

A grande questão que cativava o filósofo ora estudado em relação ao tempo, era, justamente, investigar a sua origem primeira. A gênese do tempo revela que a temporalidade é originada no fluxo absoluto de vivências, como possibilitadora das vivências temporais. Ressaltase que esse fluxo absoluto não é essencialmente temporal, pelo contrário, é ausente de tempo, é o local onde o tempo se origina. É o absoluto último e verdadeiro.

Para entrar nesse terreno árduo da busca pela origem do tempo, Husserl indica o processo de redução do tempo objetivo, ou seja, a suspensão do entendimento natural, empírico, do tempo. Deve, portanto, ser realizada uma purificação do objeto de estudo para que se possa desenvolver uma análise rigorosa e frutífera.

É indicado, então, começar a investigação pelas estruturas primitivas da consciência do tempo, pelas estruturas dos atos que temporalmente visam objetos. Para tanto, Husserl inicia a sua tarefa, na obra Lições para uma fenomenologia da consciência interna do tempo, expondo o pensamento de Brentano ${ }^{2}$ para, em seguida, criticá-lo e dar um passo adiante.

\footnotetext{
${ }_{2}^{2}$ Primeira seção da obra de Husserl: On the Phenomenology of the Consciousness of Internal Time (1893 - 1917), capítulo: Brentano's theory of the origin of time.
} 
Segundo Brentano (apud HUSSERL, 1991), a origem do tempo está nas associações originárias fundadas sobre as representações mnemônicas que se conectam imediatamente às representações perceptivas. Para ele, quando algo é percepcionado, esse algo permanece presente à consciência devido a uma modificação. Por exemplo, em uma música instrumental, para que possamos apreciar a sua melodia é necessário que se perceba o encadeamento dos sons, ou seja, é preciso que o som ouvido no presente não seja esquecido logo que cesse, pois:

Quando uma melodia soa, por exemplo, o som individual não desaparece totalmente com a cessação do estímulo, ou do movimento neural excitado, quando o novo som está soando, os sons precedentes não desapareceram sem deixar marcas, se assim fosse nós seríamos incapazes de perceber a relação entre os sucessivos sons ${ }^{3}$ (HUSSERL, 1991, p.11).

No entanto, Brentano (apud HUSSERL, 1991) sustenta que a permanência do som já passado deve ser mantida na consciência de forma modificada, pois, se todos os sons permanecessem com o mesmo status, teríamos um amontoado de sons simultâneos. É necessário, então, que o som permaneça na consciência de um modo modificado temporalmente. Assim, o som percebido num momento anterior não deve ser percebido como algo vivido no presente, mas como uma representação do som percebido como pertencente ao passado. Ou seja, é necessária uma modificação peculiar que se desenvolve, momento a momento, arranjando a experiência como hierarquizada numa escala do mais passado ao menos passado.

Ainda, expondo as idéias de Brentano, Husserl (1991) afirma que as representações temporais são cunhadas pela fantasia e que esta é a origem daquelas. A fantasia extrai um fantasma dos estímulos sensíveis percebidos logo após estes cessarem, uma representação imaginária temporalmente modificada: "Temos, portanto, descoberto a origem da representação do tempo na região da fantasia"4 (HUSSERL, 1991, p.12). Nota-se que fantasia, no sentido aqui apresentado, assume o significado preconizado por Aristóteles, ou seja, é o poder de suscitar representações, imagens, de coisas que já não mais estão presentes às sensações. (MORA, 2001)

É fato que um estímulo sensível qualquer, per se, não pode oferecer uma noção de duração, porquanto para tal é necessária uma sucessão, um desenrolar de acontecimentos. A ferramenta que Brentano (apud HUSSERL, 1991) sugeriu ser capaz de permitir o encadeamento que organiza uma sucessão das sensações, pela modificação do passado ao associar a sensação já percebida à nova sensação que a sucede, é, precisamente, a fantasia.

Ao processo de constante conexão das representações temporalmente modificadas, é dado o nome de associação originária. Ou seja, a fantasia é tida, paea Brentano, como a origem do tempo. Como conseqüência, a percepção ocorre ao se constatar um estímulo situado temporalmente no presente. Todos os outros processos de associações, conexões entre passados e entre passado e presente pertencem à fantasia: “Acreditamos ouvir uma melodia e, portanto, que ainda ouvimos o que recém passou, mas isto é apenas uma ilusão procedente da vivacidade da associação originária"5 (HUSSERL, 1991, p.14).

\footnotetext{
3 "When a melody sounds, for example, the individual tone does not utterly disappear with the cessation of the stimulus or of the neural movement it excites. when the new tone is sounding, the preceding tone has not disappeared without leaving a trace. If it had we would be quite incapable of noticing the relation among the successive tones".

4 "We have therefore discovered the origin of the representation of time in the region of phantasy".

5 "We believe that we hear a melody and therefore that we still hear what is just past, but this is only an illusion proceeding from the vivacity of the original association".
} 
Dessa forma, no exemplo da música, a apreensão de uma melodia (mais de uma nota musical em seqüência) é uma ilusão, pois é o produto de uma associação originária do que é e do que não é, do real e do irreal. Igualmente, a noção de futuro é dada pela fantasia. A partir do já vivido, ou seja, a partir do representado como passado, é fantasiada uma modificação perspectivista que possibilita a criação de uma expectativa.

Conclui-se, pela exposição da teoria Brentaniana (apud HUSSERL, 1991), que tempo passado e futuro são irreais, visto que real é somente o percebido agora. Esse presente surge para logo se tornar um novo irreal. Ao que tudo indica, o filósofo não logrou demonstrar como se dá a passagem do que agora é percebido para a representação modificada temporalmente desse percebido, assim como também não demonstrou como se dá a ligação entre as memórias e o presentemente percebido. Logo, o modo como se produz essa passagem do agora real para a irrealidade e a própria união do real do e do irreal permanecem não solucionadas por Brentano.

Após a breve exposição dos estudos de Brentano, Husserl (1991) passa a demonstrar suas falhas. Segundo ele, é uma teoria sobre a origem psicológica da representação de tempo, pois a análise brentaniana utiliza pressupostos transcendentes e empíricos, isto é, ele assume que existem objetos temporais que provocam sensações em nós, algo de fora para dentro, compartilhando, portanto, da visão positivista de mundo reinante na Europa à época.

O que fica comprometida na exposição brentaniana é a distinção entre um tempo originariamente intuído e um produzido pela fantasia:

\begin{abstract}
Se a intuição originária de tempo já é uma criação da fantasia, então o que distingue esta fantasia do temporal daquela em que estamos conscientes de algo temporal que pertence ao passado mais remoto de algo, portanto, que não pertence a esfera da associação originária e não é combinada numa consciência com a percepção atual, mas que anteriormente esteve combinada com uma percepção passada?6(HUSSERL, 1991, p.17).
\end{abstract}

A falha, apontada por Husserl (1991) na teoria de Brentano, foi indicar a fantasia como a origem do tempo, sem distinção, tanto para o que é relembrado como para a própria intuição perceptiva. Assim sendo, a intuição perceptiva de um momento presente é, desde já, um fantasma, e o que é relembrado é um fantasma de um fantasma.

Conforme Brentano (apud HUSSERL, 1991), a corrente do tempo dá-se por uma soma de fantasmas. Assim sendo, o que compromete a percepção de uma seqüência de passado, presente e futuro é a ausência de distinção entre o objeto temporal e o modo pelo qual este é doado na percepção, na recordação e na expectativa. Isso é conseqüência da indistinção entre ato, conteúdo de apreensão e objeto apreendido. O caráter decisivo dessa indistinção fica claro quando atentamos ao modo como é produzido o momento temporal. Momento que é produzido pela associação originária quando esta agrega uma seqüência continuada de representações à respectiva percepção.

Para Husserl, diferentemente de Brentano, não se encontram caracteres temporais, sucessão e duração somente nos simples conteúdos primários, mas também nos objetos

\footnotetext{
6 "If the original intuition of time is already a creation of phantasy, then what distinguishes this phantasy of the temporal from the one in which we are conscious of something temporal that belongs to the more remote past- of something, therefore, that does not belong in the sphere of original association and is not combined in one consciousness with the current perception, but that at one time was combined with a perception that is now past?".
} 
apreendidos e nos atos de apreensão. É por isso que a análise brentaniana sobre o tempo é limitada e impotente, não atentando a todos os estratos da constituição temporal (THOMÉ, 2008).

O cerne da crítica husserliana é a ausência da separação entre a constituição de conteúdos, dos objetos temporais e dos atos que doam tempo, pois para Brentano o momento de tempo era algo posto a partir da fantasia - fora do ato da percepção, da recordação e da expectativa - como um acréscimo dado na forma de um momento, ao nível de um momento de conteúdo.

Todavia, Husserl também viu méritos na teoria de Brentano, no que se refere à compreensão de que para que haja duração, sucessão e alteração é necessária uma modificação temporal, ou seja, um caráter sucessivo da consciência do tempo: "No entanto, um núcleo fenomenológico repousa nessas considerações". ${ }^{7}$ (HUSSERL, 1991, p.16).

Enfim, Brentano fez uma análise psicológica do tempo, valendo-se do conceito de fantasia. Diversamente, Husserl optou por uma análise puramente fenomenológica, almejando a distinção entre objeto e objeto temporal imanente, para aí sim questionar, a partir do campo fenomenológico reduzido, os objetos temporais imanentes nos seus modos de aparecer. A modificação temporal não é algo externo que doa aos atos constituidores de tempo nas vivências. Para ele, os objetos temporais e os atos de doação temporal possuem temporalidade na sua própria estrutura (THOMÉ, 2008).

Husserl (1991) entende que a consciência e o tempo são conceitos intimamente ligados, é uma relação de constituição. A temporalidade é imanente à consciência. Logo, não é possível compreender o tempo como um lapso percebido a partir de uma consciência que observa desde fora, concatenando o recordado e o esperado com o presente percebido para, então, formar um objeto temporal.

Desse modo, houve um distanciamento de Brentano nesse aspecto, tendo em vista que, para Husserl, o próprio perceber, enquanto doador de objetidade temporal, e os próprios objetos temporais possuem já em si, na sua estrutura, temporalidade: "Por objetos temporais no sentido específico entendemos objetos que não são somente unidades de tempo, mas que, também, contêm extensão temporal em si mesmos". ${ }^{8}$ (HUSSERL, 1991, p. 24).

Fica evidente, assim, a inovação trazida por Husserl: o objeto temporal alarga a noção de objeto, visto que o objeto é sempre uma unidade doada no tempo. Os objetos temporais são os dados e as apreensões de tempo imanentes à consciência.

Com efeito, há dois tipos de objeto temporal: os imanentes e os transcendentes. Estes (transcendentes) são constituídos pelos dados e apreensões imanentes que constituem a unidade e a identidade do objeto que transcende à consciência para se efetivar no nível perceptivelmente constituído. É nesse território que o tempo objetivo aparece, se manifesta. Para que de fato haja uma investigação fenomenológica é necessária uma redução às vivências fenomenologicamente reduzidas, do percebido à percepção, da unidade do objeto constituído à esfera constituinte de toda e qualquer unidade temporal, qual seja: a dos objetos temporais imanentes (THOMÉ, 2008).

Voltando ao exemplo da música, reduzindo-se todo o âmbito transcendente, tem-se o dado puro. Pode ser feito um estudo do próprio som, enquanto algo que surge e passa, movendo-se cada vez mais para o passado. Mediante o instituto da retenção, o som mantém sua temporalidade própria, garantindo a unidade do som que dura.

\footnotetext{
7 "However, a phenomenological core does lie hidden in these considerations".

8 "By temporal objects in the specific sense we understand object that are not only unities in time but also contain temporal extension in themselves".
} 
Pode-se também visar o som nos seus modos de doação e de aparecimento na consciência temporal, por intermédio de um fluxo constante. O tempo fenomenológico constitui-se nos fenômenos de fluxo. $O$ objeto temporal imanente surge com a doação do modo agora: "O som é dado, ou seja, eu estou consciente dele como um agora. Mas estou consciente dele como agora 'enquanto' qualquer de suas fases estiver sendo concebida como agora". ${ }^{9}$ (HUSSERL, 1991, p.26).

O desenvolver do fluxo é uma continuidade constantemente modificada que se amplia com passados cada vez mais profundos. $O$ agora perceptivo, que é a doação atual da percepção, funciona como uma âncora para as fases passadas. É importante destacar que o agora perceptivo não é entendido como o momento agora percebido, na medida em que ele é a forma do aparecimento que se relaciona com a percepção pura. Destarte, o agora percebido não é o percebido agora, nem a percepção, mas justamente uma relação entre percepção e consciência que permite a aparição do objeto temporal. Ele se desdobra constantemente numa fluência temporal.

Para Brentano, a modificação temporal ocorre nos conteúdos das representações, enquanto para Husserl essa modificação refere-se às modificações das apreensões como modificações dos modos de aparições dos objetos imanentes à consciência, aparição como o que aparece no seu como, a vivência propriamente imanente.

Na percepção, o que é propriamente percepcionado é o ponto da duração caracterizado como agora. Na extensão do que decorre, a retenção ocorre com clareza decrescente em relação à fase do agora atual. No caso de uma música, é possível perceber a melodia encadeada na medida em que a consciência visa o decurso total da duração da melodia. $\mathrm{O}$ som, à medida em que fica temporalmente mais distante, vai constantemente modificando-se em seu modo de aparição (mais ou menos passado), ou seja, o objeto som é sempre o mesmo, o que se altera é o seu modo de aparição. Nesse sentido, um mesmo objeto no seu modo de decorrer é sempre um novo outro: "Então as séries de modos de decurso que já não incluem um agora começam; a duração não é mais presente, mas passado, e continuamente afundando cada vez mais para o passado". ${ }^{10}$ (HUSSERL, 1991, p.30).

Há um modo de decurso que se liga ao agora atual e tem nele o seu ponto final, como a música, por exemplo. Há também uma continuidade que já não está em ligação com o agora atual, que são as memórias passadas, lembranças remotas. De todo modo, o agora atual, o presente, é sempre a origem de qualquer passado. É a partir desse ponto-fonte original que se dá início a um obscurecimento contínuo do objeto temporal em direção ao passado.

O agora atual não é algo estático, mas a mola mestra do fluxo que propicia o viver, em constantes agoras que se abrem para o passado e para o futuro, de modo que todo agora mesmo passado vivido aponta para um agora anterior de onde ele já fluiu, como também todo agora esperado vivido aponta para um agora posterior, para onde ele ainda fluirá. A vida é a unidade dessa perpétua fluência que emerge numa consciência originária como consciência do tempo (THOMÉ, 2008).

Conforme Maldonato (2008), Husserl questiona o conceito de tempo no próprio ponto de sua origem e de sua constituição. Na medida em que é manancial primário, o tempo sempre é irrupção de algo e não já uma composição. Foi essa ideia que levou o filósofo a introduzir a noção

\footnotetext{
9 "The tone is given; that is, $\mathrm{i}$ am conscious of it as now. But I am conscious of it as now "as long as" any of its phases is intended as now".

10 Then the series of running-off modes that no longer include a now begins; the duration is no longer actually present but past, and continuously sinking deeper into the past".
} 
de retenção: um ponto originário que liga os momentos do fluxo como a duração, o fluir e assim por diante. Não há nenhuma intenção que não esteja vinculada a uma "segunda intenção" (retenção) que a integra e a torna possível. Isso indica que a consciência não é consciência interna ao fluxo, mas no que ela conserva o conteúdo percebido, mesmo quando já não mais o é. Husserl (1991) propõe a tese de que a consciência é uma unidade em si, que é estruturalmente fluxo e não uma unidade ligada a outras unidades. Essa unidade é constitutiva da pluralidade da consciência e revela, ainda, a natureza da sequência e dos nexos entre os instantes reais que faz com que digamos que um determinado evento tem uma duração.

A origem do começo absoluto da temporalidade é a proto-impressão que, por sua vez, não é uma produção da consciência. Ela irrompe como fonte primitiva através de uma geração originária que permite as sensações de. $\mathrm{O}$ ponto-fonte é retido e constantemente modificado num movimento de retrotração ao passado. No exemplo da melodia, o som agora atual iniciado na proto-impressão passa à retenção e a retenção da proto-impressão é um agora. Frisa-se que esse som não é retido sem modificação, mas retido como algo que já passou. No entanto, a retenção em si é atual, enquanto atual retenção do som que foi.

Dessa forma, há sempre dois movimentos possíveis: um em direção à atualidade da retenção (visar) e outro em direção ao conteúdo da retenção (o que é visado). É essa duplicidade que permite distinguir o ato de perceber e o conteúdo percebido. É ela, igualmente, que possibilita pensar sobre a ocorrência do fluxo contínuo constantemente em mutação nas sucessivas retenções.

Se a proto-impressão é a origem do agora fluente, a retenção é a consciência originária do passado. Essa consciência originária que aglutina e combina presente, passado e futuro organiza e dispõe o protoproduzido temporalmente através do fluxo, ou seja, é a espontaneidade da consciência que promove e permite a fluência do protoproduzido. Destarte, a consciência do passado, do presente e do futuro ocorre numa unidade fluente e incindível. É a unidade temporal na qual operam atos que não podem atuar independentemente: a duração só é possível na relação entre agora mesmo passado e agora atual.

É possível distinguir entre a visada e o que é visto temporalmente. Não se pode, então, sequer pensar em modificações e fases de fluxo que constituem o contínuo do campo temporal. As retenções que ocorrem continuamente se dão de forma organizada, sendo que cada retenção atual modifica todas as retenções que a precederam. Assim, ocorre a modificação em toda a cadeia de retenções que propriamente já ocasionaram outras modificações. Ou seja, a partir de um pontofonte, todo um fluxo de retenções é continuamente modificado. Uma modificação temporal produz constantemente uma nova modificação, de modo que a consciência passa da impressão a retenções sempre novas.

É importante destacar que as retenções têm começo e fim, ao contrário do próprio fluxo de vivências. A fluência da corrente temporal do passado é infinita e é constante abertura que permite a unidade da própria vida. A retenção, relação entre um visar e um visado, não é uma atividade ativa do ego, mas uma modificação intencional exercida na esfera da pura passividade. Giza-se que com o desenrolar da temporalidade ocorre o constante aprofundamento do passado, a ponto de se chegar à completa escuridão, em oposição à luminosidade do momento presente.

Mas, enfim, como se pode perceber algo como passado, mais passado, ou mais presente? A diferença é intencional. É uma diferença de visada do objeto que modifica o próprio conteúdo visado. Quando ocorre uma recordação, está presente uma certa vivacidade, pois a recordação é possível por ela ter sido retida. Essa recordação primária, agora mesmo passado, é diferente de 
um objeto semelhante percebido no agora atual. De todo modo, ambas são efetuadas no momento agora, pois agora percebo e agora recordo: "para o ponto-agora da percepção corresponde um ponto-agora da recordação". ${ }^{11}$ (HUSSERL, 1991, p. 37). Do mesmo modo, a expectativa de uma percepção futura, protensão, igualmente, ocorre no presente. Não se trata, portanto, de uma comparação entre uma memória e uma imagem do momento presente e, a partir dessa comparação, o surgimento da noção de dimensão do tempo.

Husserl (1994) descreve um tipo de memória que se refere a um passado mais distante do agora atual que é a recordação secundária ou iterativa. Trata-se de uma modificação reprodutiva do agora mesmo. O objeto recordado é presentificadamente reproduzido, de modo que se tem aí uma intenção passada como que presente. Diferencia-se, assim, da recordação primária, por nela haver tão-somente a retenção e a doação de caráter agora mesmo passado, sem haver produção de uma objetividade duradoura. Na recordação secundária, entretanto, há a reprodução, o reavivamento de uma unidade temporal duradoura que acrescenta elementos que não estavam presentes na impressão. É uma fantasia. A reiteração ocorre de forma completa não quando se relembra de um retalho ou de algum elemento estanque do passado, mas, sim, quando o objeto é reconstituído integralmente num fluxo de presentificações, ou seja, quando é como que percepcionado de novo.

A compreensão da estrutura da recordação iterativa foi insuficientemente explicitada por Brentano, pois ele não percebeu que a fantasia nunca é por si mesma, que ela não pode doar originalmente o objeto temporal, porque já é sempre fundada em percepções e retenções. $O$ dado presentificado deve necessariamente remeter ao originalmente dado na vivência, o objeto temporal doado na percepção, visto que, caso a apreensão do tempo residisse exclusivamente na fantasia, não haveria propriamente um decurso temporal, mas somente fantasias de fantasias, isto é, a fantasia produziria apenas fases da duração sem qualquer posição original, sem relação ao agora atual (THOMÉ, 2008).

Segundo Husserl (1991), há a primazia hierárquica do ato da percepção no ato de constituição do tempo, pois é pela percepção que ocorre a doação do presente. A apreensão de algo, seja como presente, passado ou futuro, sempre ocorre num ponto agora percepcionado, haja vista que é pela percepção que ocorre a noção da continuidade de objetos apreendidos. É a partir do agora atual que ocorre a organização e a noção de passado, futuro e presente.

Em síntese, a estrutura do passado é exposta mediante um agora mesmo passado, na recordação primária, ou um como que agora na recordação iterativa, enquanto o futuro é exposto segundo a forma de um ainda-não-agora. A doação originária da expectativa não é um produto da consciência, uma fantasia, tendo em vista que essa doação ocorre sempre no presente vivo. É basilar na compreensão da protensão a noção de horizonte, o que aponta para uma abertura: tudo o que é visto desde o limite do presente vivo. Os limites de visibilidade e constituição do futuro se dão no presente vivo.

$\mathrm{Na}$ abertura do horizonte de futuro como possibilidades ocorre o preenchimento de uma intenção vazia que modifica toda a cadeia de preenchimentos possíveis. É justamente essa a condição possibilitadora da irrupção do fluxo temporal, é o horizonte vazio que possibilita o aparecimento do presente vivo. A compreensão do horizonte do futuro como fundo não preenchido garante ao objeto temporal pura possibilidade para fluir. Isso significa ao mesmo tempo que ele pertence a um único infinito fluxo de vivido. É essa dinâmica de um futuro sentido

11 "To the now point of the perception corresponds a now-point of the memory". 
de fundo, de um presente vivido e de um passado que possibilita, num constante fluxo, as condições para uma unidade da consciência do tempo (THOMÉ, 2008).

Todas as vivências têm duração enquanto momento de continuidade do fluxo. $O$ que se vive pode, com o decorrer do tempo, findar-se, porém o fluxo em si não tem início ou fim, ele engloba a totalidade de vividos.

Destaca-se que esse tempo fenomenológico não se confunde com o tempo natural, científico, tratando-se aqui do tempo imanente ao eu puro. A vivência pode ser visada, portanto, de forma natural, real, ou como tempo pessoal, imanente, no seu modo como aparece temporalmente:

A forma fundamental desta síntese universal, que faz possível todas as sínteses restantes da consciência, é a consciência imanente do tempo, que engloba tudo. Seu correlato é a própria duração imanente, em virtude da qual todos os estados do eu, acessíveis à reflexão, têm que se apresentar como temporalmente ordenados, começando e acabando no tempo, simultaneamente e sucessivamente, no horizonte constante e infinito do tempo imanente (HUSSERL, 1986, p. 91).

A percepção de uma multiplicidade de vivências relacionadas surge de uma atividade de síntese, de momentos isolados, da consciência:

Cada experiência isolada é um emergir à consciência, já sempre pressuposta como unitária em relação a seus momentos constituintes, os quais não criam a consciência, mas se desenvolvem nela, dando lugar à sua unidade (MALDONATO, 2008, p.43).

Para Maldonato (2008), seu fundamento, portanto, é a temporalidade imanente, o fluxo de vida que se constitui em si e por si, no qual se articula a consciência originária do tempo, isto é, daquela consciência, já sempre pressuposta, que assume a forma das objetividades do mundo. É possível também uma visada mais profunda que enfoca o modo de doação temporal, na percepção do agora atual, na retenção do ainda há pouco e na protensão do ainda não. Vislumbrase a vivência em três direções: do antes, do depois e do agora. Porém, em toda vivência atual estão embutidas as vivências passadas e as esperadas. Logo, nas vivências, há uma comunhão dos três horizontes de tempo sempre em simultaneidade, e é nesse horizonte triplo que se efetiva a fluência infinita.

Alves resume de modo exemplar os principais elementos da dinâmica de tempo exposta por Husserl ao destacar dois aspectos da intuição do tempo por referência a um objeto temporal:

A doação da fluência (a consciência de sucessão) e a configuração das modalidades da orientação temporal do presente, passado e futuro - a descrição da conexão entre protoimpressão, constitutiva do 'agora', e a recordação fresca (mais tarde alterada na teoria da retenção), bem como a relação entre a percepção e os actos reprodutivos da recordação iterativa, enquanto actos que visam o presente e o passado, realizam, respectivamente, uma descrição fenomenológica da doação da fluência e de um tempo orientado, por referência aos pontos zero do 'presente' e do par.(ALVES, 2008, p. 164).

Apresentados os conceitos de consciência, subjetividade e tempo sob o viés fenomenológico, passar-se-á, no próximo capítulo, a um estudo investigativo de como a subjetividade se constitui a partir da temporalidade. 


\section{Considerações finais}

No presente trabalho foi efetuada a exposição, no primeiro capítulo, do itinerário filosófico de Edmund Husserl. No segundo, foram apresentados os conceitos de consciência, subjetividade e de tempo, sob o ponto de vista husserliano. No terceiro capítulo, com suporte nos conceitos explicitados no capítulo anterior, foi exposta a relação originária estabelecida entre subjetividade, consciência e tempo.

De fato, investigar o tempo em sua origem primeira foi um tema que despertou grande interesse em Husserl. A sua apresentação da gênese do tempo revelou que a temporalidade é originada no fluxo absoluto de vivências que, consequentemente, como possibilitadora das vivências temporais, é a origem da subjetividade.

Dessa forma, a subjetividade é possível pela (e por intermédio da) temporalidade que, por sua vez, dá início à vida subjetiva e permite a sua expansão pelas vivências temporais. Frisa-se que esse fluxo absoluto não é essencialmente temporal. Pelo contrário, é ausente de tempo, é o local onde o tempo se origina. Em síntese, é o absoluto último e verdadeiro.

Observou-se também que é nessa relação autogênica essencial que são criadas as condições para o desenrolar da vida subjetiva em unidade, cujo processo é caracterizado pela abertura ao tempo, que não se dá no futuro ou no passado, sendo um fluir na perpetuidade viva do presente.

Por fim, cabe destacar que este trabalho visou tão somente apresentar alguns dos principais conceitos expostos por Husserl. A apresentação foi desenvolvida de forma simples, não sendo apontadas falhas ou incongruências que porventura o filósofo tenha apresentado, por ser essa uma tarefa que ultrapassaria os limites do objetivo deste texto. No entanto, pode ser facilmente constatado o surgimento, nos anos que sucederam a sua morte, de inúmeras críticas às teorias de Husserl. 


\section{Referências}

ALVES, Pedro Manuel dos Santos. Tempo objectivo e experiência do tempo: a fenomenologia husserliana do tempo perante a Relatividade Restrita de A. Einstein. Investigaciones fenomenológicas, Madrid, n. 6, p. 145-180, Maio de 2008.

CESCON, Everaldo. A doutrina husserliana da consciência. Um estudo a partir das Investigações Lógicas $\left(\mathrm{V}^{\mathrm{a}}\right)$ e das Meditações Cartesianas. Dialegesthai. Rivista telematica di filosofia [in linea], anno 11 (2009) [inserido dia 20 de dezembro de 2009], disponível na World Wide Web: http://mondodomani.org/dialegesthai, [94 KB], ISSN 1128-5478.

GOTO, Tommy Goto. Introdução à Psicologia Fenomenológica: a nova psicologia de Edmund Husserl. São Paulo: Paulus, 2008.

HEIDEGGER, Martin. Ser e tempo. Petrópolis: Vozes, 1995.

HUSSERL, Edmund. On the Phenomenology of the Consciousness of Internal Time (1893 - 1917). Traduzido por John Barnett Brough. Dordrecht: Kluwer Academic Publishers, 1991.

HUSSERL, Edmund. A idéia da fenomenologia. Lisboa: Edições 70, 1986. 95 p.

HUSSERL, Edmund. A crise da humanidade européia e a filosofia. Introd. e Trad. ZILLES, Urbano. 2.ed. Porto Alegre: EDIPUCRS, 2002. 96 p.

HUSSERL, Edmund. Investigaciones lógicas. 2.ed. Madrid: Revista de Occidente, 1967. 2 v.

HUSSERL, Edmund. Lições para uma fenomenologia da consciência interna do tempo. Trad. Pedro M. S. Alves. Lisboa: Imprensa Nacional Casa da Moeda,1994.

HUSSERL, Edmund; LOPARIC, Zeljko; LOPARIC, Andréa Maria Altino de Campo; MERLEAU-PONTY, Maurice. Investigações lógicas: sexta investigação: elementos de uma elucidação fenomenológica do conhecimento. São Paulo: Nova Cultural, 1988. xv, 189 p.

MERLEAU-PONTY, Maurice. Meditaciones cartesianas. 2.ed. México: Fondo de Cultura Económica, 1986. 230 p.

MERLEAU-PONTY, Maurice. Investigações lógicas. Segundo volume, Parte I: Investigações para a Fenomenologia e a Teoria do Conhecimento. De acordo com o texto de Husserliana XIX/1, editado por Úrsula Panzer. Trad. de Pedro M. S. Alves e Carlos Aurélio Morujão. Lisboa: Centro de Filosofia da Universidade de Lisboa, 2007.

LYOTARD, Jean-François. A fenomenologia. Tradução de Mary Amazonas Leite de Barros. São Paulo: Difusão Européia do Livro, 1967. 130 p.

MALDONATO, Mauro. Consciência da temporalidade e temporalidade da consciência. Tradução de Roberta Barni. Revista Latinoamericana de Psicopatologia Fundamental, São Paulo, v. 11, n. 1, p. 39-54, março 2008.

MORA, Jose Ferrater. Dicionário de Filosofia. São Paulo: Loyola, 2001.

ONATE, Alberto Marcos. A noção husserliana de subjetividade transcendental. Veritas, Porto Alegre, v. 51, n. 2, p. 109-116, Junho 2006.

SHUHMANN, Karl. Husserl- Chronik. Denk-und Lebensweg Edmund Husserls. Netherlands: Martinus Nijhoff/The Hague, 1977.

THOMÉ, Scheila Cristiane. Subjetividade e tempo na fenomenologia husserliana. Curitiba: Universidade Federal do Paraná, Dissertação de Mestrado, 2008.

ZITKOSKI, J. J. O método fenomenológico de Husserl. Porto Alegre: EDIPUCRS, 1994.

Autor(a) para correspondência / Corresponding author: Everaldo Cescon. ecescon@ucs.br 